\title{
Comparative Study between Neopterin and Alvarado Score in the Diagnosis of Acute Appendicitis and Its Severity
}

\author{
Zuhair B. Kamal ${ }^{1}$, Raghad E. Naji ${ }^{2 *}$, Hiba A. Ali ${ }^{3}$ \\ ${ }^{1}$ Consultant General Surgeon, Al-Kindy College of Medicine, University of Baghdad, Baghdad, Iraq; ${ }^{2}$ Clinical Biochemistry, \\ Al-Kindy College of Medicine, University of Baghdad, Baghdad, Iraq; ${ }^{3}$ Department of Surgery, Al-Kindy Teaching Hospital, \\ Baghdad, Iraq
}

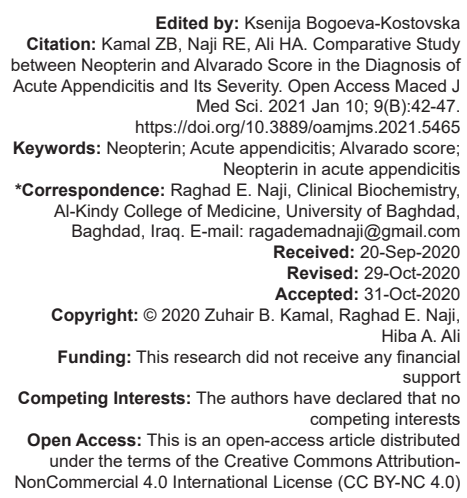

\section{Abstract}

BACKGROUND: Acute appendicitis (AA) remains a complex case even for experienced surgeons. Rate of negative appendectomy is $5-40 \%$ and delayed intervention result in perforated appendicitis in $5-30 \%$ of cases.

AIM: The aim of the study was to evaluate NPT as a marker for the diagnosis of AA concerning its severity. And compare the diagnostic value of it with the ALV scoring system.

METHODS: One hundred twenty patients presented with signs and symptoms of AA and underwent appendectomy, only 84 patients proved to be AA by histopathological examination, were included in the study. Blood samples fo neopterin (NPT) estimation and Alvarado (ALV) score was calculated. Control group consists of 45 healthy individual.

RESULTS: NPT levels were significantly higher in patients' group than control with $p=0.001$ at a cutoff poin $5.3 \mathrm{nmol} / \mathrm{L}$. The diagnostic accuracy of NPT was higher than ALV score. NPT sensitivity, specificity, positive predictive value, and negative predictive value were $85.4 \%, 76.9 \%, 89 \%$, and $70 \%$, respectively.

CONCLUSION: NPT significantly elevated in patient with AA and has a high diagnostic accuracy, with correlation to clinical features and severity of the inflammation.

\section{Introduction}

Acute appendicitis (AA) is a common abdominal emergency with a life time prevalence of about $7 \%$. The clinical diagnosis of $A A$ remains a challenge to surgeons. The clinical diagnosis helps in patients who presented with classical signs and symptoms, but a typical presentations may end in diagnostic confusion and delay in management which will increase the possibility of complications, including appendicular mass, appendicular perforation, sepsis, and even death. Symptoms are usually not specific and overlap with other diseases. Despite all improvement in clinical and laboratory diagnosis and the multiple scoring systems to guide the diagnosis, the decision to operate or not remains challenging [1].

AA can affect people at any age, usually between the ages of (10 and 30 ) years, slightly more common in males, with a male to female ratio $1.4: 1$. Perforation is found in about 13-20\% of patient with AA [2]. Appendicitis is a multi-factorial disease, but faecoliths, foreign body, malignancy, and lymphoid hyperplasia during an infection are possible causes. Negative appendectomy might not only expose the patient to the risk of surgical operation but also increase the risk of myocardial infarction related to surgical removal of appendix and tonsils as it has been reported [3].

Diagnostic approaches include history of present illness, physical examination, laboratory tests, and imaging modalities.

Abdominal pain is the main presenting complain in patients with AA started usually as an umbilical colicky pain then become sharp and constant which migrate to the right iliac fossa. Other symptoms such as loss of appetite, nausea, and vomiting may also present. Less typical symptoms warrant a period of observation and re-evaluation, this approach could result in unnecessary prolong hospital stay and delayed management [2]. On clinical examination, right lower abdominal tenderness on palpation is the most important finding which may or may not be associated with rebound tenderness [3].

Many laboratory investigations used to help in the assessment of a patient with suspected AA, for example, urine analysis, which may reveal another diagnosis such as urinary tract infection or renal stone, blood tests may reveal elevated white blood cell (WBC), elevated $C$ reactive protein $(C R P)$ which makes appendicitis more likely [4]. 
Imaging modalities such as plain abdominal X-ray may show air-fluid level localized to the caecum and terminal ileum with increased soft tissue density in the right lower quadrant. Ultrasound is useful for the diagnosis of AA and exclusion of other causes such as renal stone, lymphadenitis, pelvis inflammatory disease, ruptured ovarian cyst, and ectopic pregnancy. Computed tomography (CT) with intravenous contrast is more useful and accurate, but it is more expensive, time consuming, and expose the patient to high rate of radiation. Unfortunately, both ultrasound and CT results are operator dependent. Finally, magnetic resonance imaging has benefits in pregnant women with right lower quadrant pain. Features of fluid filled appendix and more than $7 \mathrm{~mm}$ in diameter were suggestive [4].

Multiple clinical scoring systems have been designed for the diagnosis of AA such as Alvarado (ALV) Score which is the most commonly used, modified ALV score, RIPASA score, and other [5].

Neopterin (NPT) was first isolated from larvae of bees, in worker bees in royal jelly in 1963, and subsequently from human urine by Sakurai and Goto in 1967 [6].

Biochemically, it derives from guanosine triphosphate, it belongs to the chemical group known as pteridines. It is synthesis from human monocytederived macrophage and dendritic cells upon stimulation with pro-inflammatory cytokine interferongamma. Increased NPT concentrations are commonly observed with diseases in which the cellular ( $\mathrm{T}$-helper 1 [TH1]-type) immune system is involved. These include primarily infections with viruses and intracellular bacteria, auto-immune syndromes, malignancies, and allograft rejection episodes. Measurement of NPT concentrations in body fluids such as blood, serum, spinal fluid, and urine provides information about activation of cellular system in human, under control of TH cells type 1 [7].

High NPT production is associated with increased production of reactive oxygen species. NPT is also used to estimate the extent of oxidative stress elicited by the immune system [7].

NPT could be elevated in infections whether viral (HIV), bacterial (Escherichia coli, Borrelia, and Helicobacter pylori), or parasitic (malaria), auto-immune diseases such as rheumatoid arthritis and systemic lupus erythematous. Furthermore, in malignant tumor (gynecological and hematological tumors) and allograft rejection episodes. Blood NPT concentrations are age-dependent, being higher in children and elderly people [8], [6].

The objective of the study was to evaluate NPT as a marker for the diagnosis of AA concerning its severity. And compare the diagnostic value of it with the ALV scoring system.

\section{Materials and Methods}

This case-control study was conducted in the Emergency Department at Al-Kindy Teaching Hospital between February 2018 and September 2018, where the patients were suspected of having AA presenting with acute abdominal pain of $<48 \mathrm{~h}$ duration and were operated on after full history taking, clinical examination, and essential laboratory tests were done. Samples from the healthy individuals were collected as a control group.

A pre-check list was filled through direct interview with the patient, the chick list included: Age, gender, NPT level, and ALV score.

The decision of appendectomy was solely based on surgeon's clinical judgment after taking into consideration all the findings of clinical, laboratory, and radiological investigations.

Patients were monitored following admission, surgery until discharged well form the hospital. The daily follow-up included monitoring of vital signs, general appearance, and abdominal examination.

The patients underwent appendectomy under general anesthesia in the emergency theatres at Al-Kindy Teaching Hospital. The final diagnosis was done by histopathology examination of the resected specimen macroscopically and microscopically. All of the specimen was investigated in the Histopathology Department at Al-Kindy Teaching Hospital. Where mild AA defined as acute mucosal and submucosal inflammation while severe AA defined as suppurative and gangrenous appendicitis.

\section{Inclusion criteria}

All patients aged above 16-year-old suffered from signs and symptoms suggesting $A A$ within $48 \mathrm{~h}$ duration.

ALV score (Table 1) is a 10-clinical scoring system based on history, physical exam, and laboratory investigation to describe the likelihood of AA. Those with low scores are unlikely to have AA. Score $5-6$ is possible for AA, score $7-8$ is probable, and score $>9$ is very probable.

From each patient, an extra $5 \mathrm{ml}$ of blood was collected in the ER. Samples were assayed according

\section{Table 1: ALV score}

\begin{tabular}{ll}
\hline Signs and symptoms & Score \\
\hline Migratory of pain to the right iliac fossa & 1 \\
Anorexia & 1 \\
Nausea and vomiting & 1 \\
Tenderness in the right iliac fossa & 2 \\
Rebound tenderness & 1 \\
Body temperature more than $37.5^{\circ} \mathrm{C}$ & 1 \\
Laboratory findings & \\
WBC count $>10.0 \times 9 / \mathrm{L}$ & 2 \\
Shift to the right neutrophils & 1 \\
Total score & 10 \\
\hline ALV: Alvarado; WBC: White blood cell. &
\end{tabular}


to the manufacture's recommended procedure by trained biochemist at Al-Kindy College of Medicine Biochemistry Lab.

This enzyme immunoassay is evaluated for the manual use and especially for the automated use with (Dade Behring Holdings, Inc., Germany) ELISA processor for the determination of NPT in serum.

\section{Statistical analysis}

The collected data were introduced in the Microsoft excel sheet and located into the IBM-SPSS version 24 statistical package was used in statistical analysis.

Descriptive statistical analysis was presented using mean \pm standard deviation (SD), frequency distribution tables, and graphs.

Inferential statistic was displayed using tow sample t-test, Chi-squared test, measurement of diagnostic accuracy, sensitivity, specificity, positive predictive value (PPV), and negative predictive value (NPV).

Receiver operating characteristic (ROC) curves with calculation of total area under the curve (TAUC) and the significance of the result were measured and coordination of the curves was presented in tables to calculate sensitivity and specificity of the test at different cutoff points.

$p<0.05$ was considered as the cutoff point for discrimination of significances.

\section{Results}

A total of 120 patients had been seen in the emergency department (ED) with signs and symptoms of AA which underwent appendectomies, only 84 patients were proven AA by histopathology examination. The mean age were $23.24 \pm 6.74,58 \%$ of patients were male and $42 \%$ were female, as shown in Figure 1 (distribution of cases according to gender).

Table 2 and Figure 2 (distribution of cases according to severity) show that $31 \%$ of appendicitis

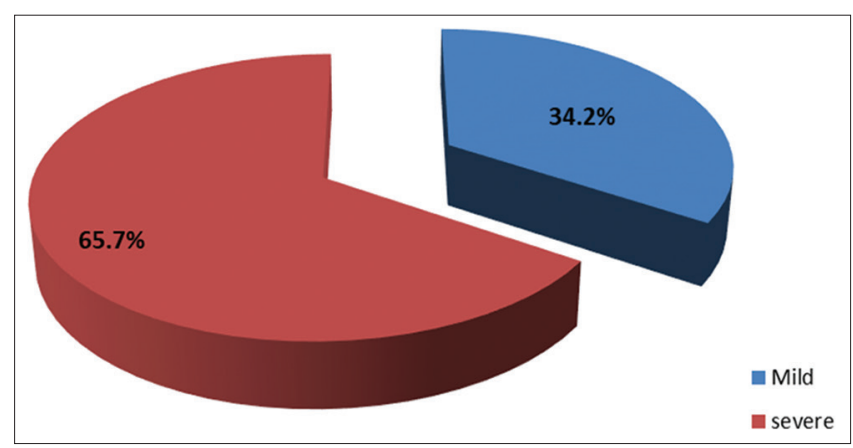

Figure 1: Distribution of cases according to gender were mild and $69 \%$ were severe, the mean of the ALV score was $7 \pm 1.4,42.9 \%$ of cases got the score (5-6), in the rest of the patients the score was more than 6 . The mean NPT level was $12.53 \pm 1.57 \mathrm{nmol} / \mathrm{L}$, $34.5 \%$ of studied patient scored low NPT level $(<5.3$ $\mathrm{nmol} / \mathrm{L})$.

Table 2: Distribution of studied cases according to essential studied characteristics

\begin{tabular}{llll}
\hline Parameter & Number & Percentage (\%) & Mean \pm SD \\
\hline Gender & & & \\
$\quad$ Male & 49 & 58 & \\
$\quad$ Female & 35 & 42 & $12.53 \pm 1.57$ \\
$\quad$ Neopterin level & & & \\
$\quad$ Low & 29 & 34.5 & $7 \pm 1.4$ \\
$\quad$ High & 55 & 65.5 & \\
Alvarado score & & & \\
$\quad 5$ and 6 & 36 & 42.9 & \\
$\quad>6$ & 48 & 57.1 & \\
Severity of appendicitis & & & \\
$\quad$ Mild & 26 & 31 & \\
$\quad$ Severe & 58 & 69 & \\
\hline
\end{tabular}

Figures 3 and 4 show the severity of appendicitis in male and female patients, respectively.

In Table 3, the mean NPT level among the case group was significantly higher than that of the control group with $p=0.001$.

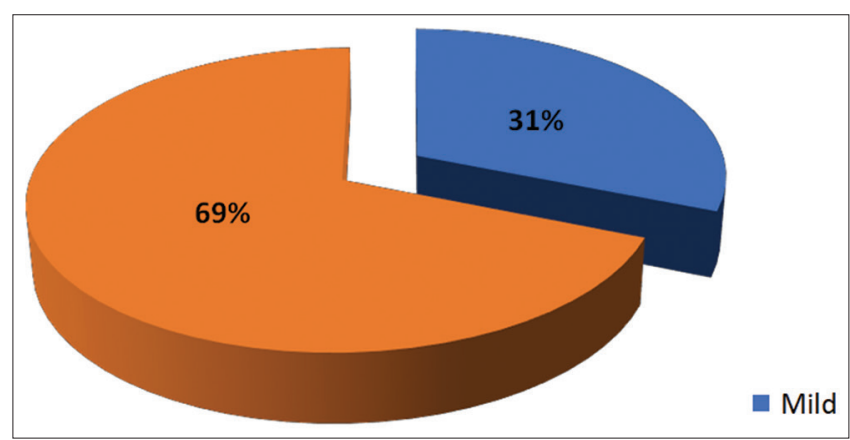

Figure 2: Distribution of cases according to severity

In Table 4, a significant association between high NPT level and severe appendicitis with $\mathrm{p}=$ 0.001 . Table 5 showed that NPT was more sensitive yet less specific than that in ALV score, and the diagnostic accuracy of NPT was higher than that of the score.

Figures 3 and 4 show the severity of appendicitis in male and female patients, respectively, while Tables 6-8 show the association between NPT and the ALV score, and severity of appendicitis in the same patients.

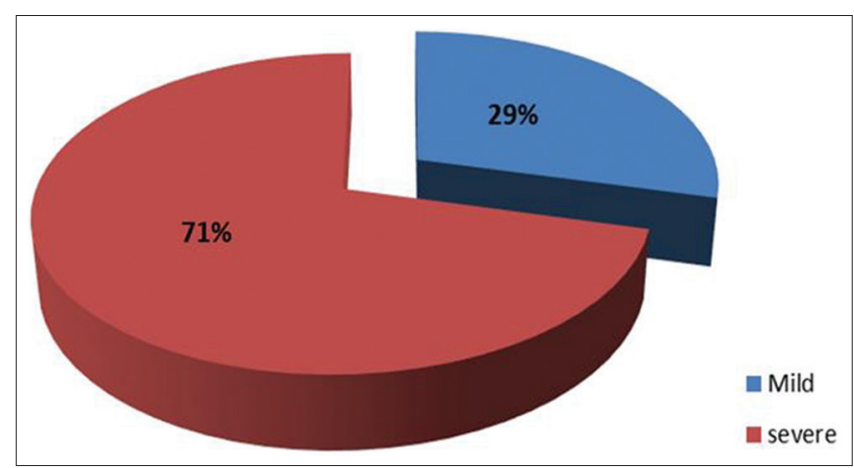

Figure 3: Severity of appendicitis in male patients 


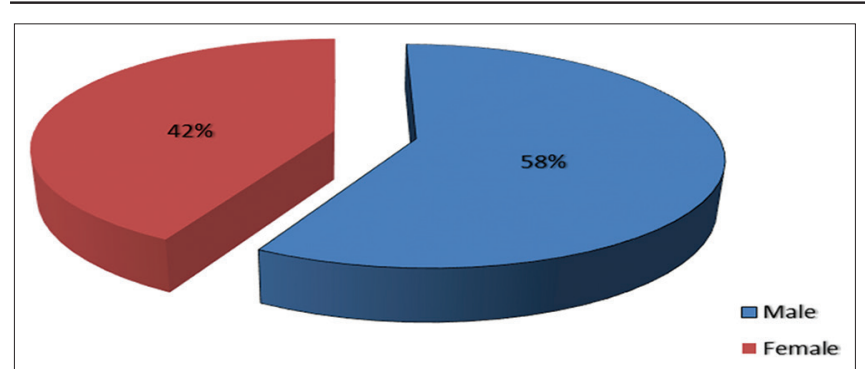

Figure 4: Severity of appendicitis in female patients

\section{Discussion}

For the past two centuries, AA has been the most common indication for emergent abdominal surgery. The rate of diagnostic errors of AA cases still remains approximately $20-45 \%$ despite the widespread use of imaging techniques and clinical scoring systems [9], [10]

Table 3: Two sample $t$ test of NPT level among cases and control groups

\begin{tabular}{lllll}
\hline Parameter & Number & Mean \pm SD & & p-value \\
\hline Cases & 84 & 12.5321 & 1.57407 & 0.001 \\
Control & 45 & 5.9613 & 3.70189 & \\
\hline
\end{tabular}

Ultrasound and CT abdomen can improve the diagnostic accuracy of AA. Ultrasound is usually helpful in the hands of an expert operator, although CT abdomen have a high accuracy rate for the diagnosis of AA but its more expensive, time consuming and has a risk of radiation exposure. Hence, there is a need for accurate plasma markers which can improve the diagnosis of AA and reduce the requirement for abdominal imaging [11]

Table 4: Association of NPT and ALV score with severity in all cases

\begin{tabular}{|c|c|c|c|c|c|}
\hline \multirow[t]{2}{*}{ Variables } & \multicolumn{2}{|c|}{ Severe } & \multicolumn{2}{|l|}{ Mild } & \multirow[t]{2}{*}{$p$-value } \\
\hline & Count & Column $n \%$ & Count & Column n\% & \\
\hline \multicolumn{6}{|l|}{ Neopterin } \\
\hline High & 49 & 84.5 & 6 & 23.1 & \multirow[t]{2}{*}{0.001} \\
\hline Low & 9 & 15.5 & 20 & 76.9 & \\
\hline \multicolumn{6}{|l|}{ Alvarado } \\
\hline$>6$ & 43 & 74.1 & 5 & 19.2 & \multirow[t]{2}{*}{0.001} \\
\hline $5-6$ & 15 & 25.9 & 21 & 80.8 & \\
\hline
\end{tabular}

A recent study in Turkey by Kose et al. showed that the development and/or use of scoring systems do not significantly improve the diagnostic accuracy of AA [5]. Hence, new studies have been made to evaluate some inflammatory markers as a discrimination factors in patient with AA such as interleukin 6 (IL-6), S100A8/ A9, CRP, and NPT [12], [13], [14], [15].

Table 5: Comparison between NPT and ALV score sensitivity, specificity, PPV, NPV, and accuracy

\begin{tabular}{lll}
\hline Parameter & NPT (\%) & ALV (\%) \\
\hline Sensitivity & 85.4 & 74.1 \\
Specificity & 76.9 & 80.8 \\
PPV & 89 & 89.6 \\
NPV & 70 & 58.3 \\
Accuracy & 82.1 & 76.2 \\
\hline NPT: Neopterin; ALV: Alvarado; PPV: Positive predictive value; NPV: Negative predictive value.
\end{tabular}

NPT is a low molecular weight aromatic pteridine molecule produced mainly by activated monocytes and macrophages, and it serves as a marker for cellular immune system activation [16]. It is shown that there is an increase in the levels of NPT with sepsis, bacterial and viral infections, and malignancy [6].
Table 6: NPT and ALV score presented as total area under the curve (all studied cases)

\begin{tabular}{lllll}
\hline Test result variable (s) & Area & Std. Error $a$ & p-value & $\begin{array}{l}\text { 95\% confidence interval }(\mathrm{Cl}) \\
\text { (Lower bound-Upper bound) }\end{array}$ \\
\hline NPT & 0.862 & 0.041 & 0.001 & $(0.783-0.941)$ \\
ALV & 0.860 & 0.039 & 0.001 & $(0.783-0.937)$ \\
\hline
\end{tabular}

A study of Eisenhunt., which is done in UK, found that NPT level is significantly elevated in patient with virus infection such as dengue and measles and that the level of NPT correlates with the severity of the disease [17]. Another study by Fisgin et al., which is done in Turkey, found that NPT can be a predictor of the severity of sepsis and there is correlation between serum NPT level and the mortality rates. Its increased concentrations are related to the endothelium damage. Therefore, NPT found to be a prognostic factor in patients with sepsis [17].

Table 7: Association between NPT level, ALV score, and severity of appendicitis in male cases

\begin{tabular}{|c|c|c|c|c|}
\hline \multirow[t]{2}{*}{ Variables } & \multicolumn{2}{|l|}{ Severe } & \multicolumn{2}{|l|}{ Mild } \\
\hline & Count & $\mathrm{n} \%$ & Count & $\mathrm{n} \%$ \\
\hline \multicolumn{5}{|l|}{ NPT } \\
\hline High & 30 & 85.7 & 4 & 28.6 \\
\hline Low & 5 & 14.3 & 10 & 71.4 \\
\hline \multicolumn{5}{|c|}{ Sensitivity $=85.7 \%$, specificity $=71.4 \%$, PPV $=88 \%$, NPV $=66.6 \%$, accuracy $=81.6 \%$} \\
\hline \multicolumn{5}{|l|}{ ALV } \\
\hline$>6$ & 23 & 65.7 & 2 & 14.3 \\
\hline $5-6$ & 12 & 34.3 & 12 & 85.7 \\
\hline
\end{tabular}
ALV: Alvarado.

In this study, we analyzed 84 patients presented with signs and symptoms of AA. Their mean age was $23.24 \pm 6.74$, and they were 35 females and 49 males. We evaluate the diagnostic value of NPT at a cutoff value $5.3 \mathrm{nmol} / \mathrm{L}$ and ALV score $\geq 7$.

Table 8: Association between NPT level, ALV score, and severity of appendicitis in female cases

\begin{tabular}{|c|c|c|c|c|}
\hline \multirow[t]{2}{*}{ Variables } & \multicolumn{2}{|l|}{ Severe } & \multicolumn{2}{|l|}{ Mild } \\
\hline & Count & $n \%$ & Count & $n \%$ \\
\hline \multicolumn{5}{|l|}{ NPT } \\
\hline High & 19 & 82.6 & 2 & 16.7 \\
\hline Low & 4 & 17.4 & 10 & 83.3 \\
\hline \multicolumn{5}{|c|}{$\begin{array}{l}\text { Sensitivity }=82.6 \%, \text { specificity }=83.3 \%, \text { PPV }=90.4 \%, \text { NPV }=71.4 \% \text {, accuracy }=82.8 \% \text {. } \\
\text { ALV }\end{array}$} \\
\hline$>6$ & 20 & 87.0 & 3 & 25.0 \\
\hline $5-6$ & 3 & 13.0 & 9 & 75.0 \\
\hline
\end{tabular}

We found significant differences in the plasma concentration of NPT in patients with AA compared to control group. NPT diagnostic accuracy was higher than ALV score (82.1\% and $76.1 \%$, respectively). Both the NPT and ALV score were correlated with the severity of AA with a $p=0.001$ for each.

In all studied cases, NPT was more sensitive but less specific than ALV score. While NPV was higher with NPT test than ALV score, yet the PPV was almost the same in all cases.

Clinical usefulness depends mainly on cutoff points that most accurately discriminate between patients with AA and those without. To find this cutoff point, ROC curves were calculated and the ideal cutoff point was assessed as the maximum sum of sensitivity and specificity of the marker. The overall accuracy of the marker was presented by the area under the curve (AUC). 
In our study, the AUC of NPT was found to be slightly higher than that of ALV score, while the $\mathrm{Cl}$ were 0.783-0.941 and 0.783-0.937 for NPT and ALV score, respectively, for all cases. In male patients group, NPT was more sensitive with higher diagnostic accuracy than ALV score with $81.6 \%, 65.7 \%$, and $71.4 \%$, respectively. In female patients' group, ALV score was more sensitive than NPT with $87 \%$ and $82.6 \%$, respectively, while the diagnostic accuracy was the same $(82.8 \%)$.

NPT was found to be more sensitive in male patient group than female patient group, while females patient group had a higher PPV. Compared to ALV score, NPT was more sensitive in male patients group, while in female patient group, NPT was less sensitive.

A similar study had been conducted in Turkey by Dal, where 100 patients studied for serum CRP, procalcitonin, and NPT and which were significantly higher in patients with focal appendicitis. They concluded that these markers diagnostic value and should be correlated with clinical features [18].

Another study in Turkey about the role of NPT levels in the diagnosis of AA but on rabbits which suggest that NPT could be used as marker in the diagnosis of AA. The sensitivity, specificity, PPV, and NPV were $87.5 \%$, $100 \%, 100 \%$, and 78.5 , respectively [19].

In a patient with clinically atypical presentation of $A A$ and non-specific signs and symptoms, usually kept for observation and re-evaluation which may result in unnecessary prolong hospital stay and might be a delayed definitive treatment. This study shows that NPT can help to identify people who are more likely to have AA and can decrease the need for unnecessary hospital admissions and to consider an early appendectomy in cases with significantly high NPT level to decrease postoperative complication.

\section{Conclusion}

NPT was found to be a sensitive, non-specific test with high PPV and high diagnostic accuracy. Hence, it can decrease the false positive patients, the admissions for observation, and the unneeded appendectomies.

NPT has a good correlation with the severity of the inflammation of the appendix. Higher levels of NPT indicate a priority for surgical intervention before complications develop and may offer better anticipation for the difficulty of the operation and a possible complication.

Although NPT had a higher sensitivity in the male patient group than female patient group, the diagnostic accuracy was the same.

\section{Acknowledgment}

Special thanks are given to the surgery department in Al-Kindy College of Medicine and Al-Kindy Teaching Hospital for their help and support.

\section{Ethical consideration}

The proposal of the study was fully discussed and approved by the researcher and the ethical committee of Arabic board of surgery before the researcher starts collecting data. The agreement of health authority of Al-Kindy Teaching Hospital was approved before starting the study.

\section{References}

1. Weledji EP. The dilemma of acute appendicitis. In: Actua Problems of Emergency Abdominal Surgery. London: In Tech; 2016. https://doi.org/10.5772/63097

2. Lewis SR, Mahony $\mathrm{P}$, Simpson J. Appendicitis. BMJ. 2011;343:d5976. https://doi.org/10.1136/bmj.d5976

PMid:21980077

3. Bradley AC, Hutson MS, Kyle JA. Acute appendicitis in adults. US Pharm. 2019;44(12):HS2-9.

4. Petroianu A. Diagnosis of acute appendicitis. Int $\mathrm{J}$ Surg. 2012;10(3):115-9. PMid:22349155

5. Kose E, Hasbahçeci M, Aydın MC, Toy C, Saydam T, Zsoy A, et al. Is it beneficial to use clinical scoring systems for acute appendicitis in adults? Ulus Travma Acil Cerrahi Derg. 2019;25(1):12-9. https://doi.org/10.5505/tjtes.2018.22378 PMid:30742281

6. Eisenhut M. Neopterin in diagnosis and monitoring of infectious diseases. J Biomark. 2013;2013:196432. PMid:26317013

7. Gieseg SP, Baxter-Parker G, Lindsay A. Neopterin, inflammation, and oxidative stress: What could we be missing? Antioxidants (Basel). 2018;7(7):80. https://doi.org/10.3390/antiox7070080 PMid:29949851

8. Murr C, Widner B, Wirleitner B, Fuchs D. Neopterin as a marker for immune system activation. Curr Drug Metab. 2002;3(2):175-87. https://doi.org/10.2174/1389200024605082 PMid:12003349

9. Di Saverio S, Birindelli A, Kelly MD, Catena F, Weber DG, Sartelli $M$, et al. WSES Jerusalem guidelines for diagnosis and treatment of acute appendicitis. World J Emerg Surg. 2016;11:34

PMid:27437029

10. Debnath J, George RA, Ravikumar R. Imaging in acute appendicitis: What, when, and why? Med J Armed Forces India. 2017;73(1):74-9. https://doi.org/10.1016/j.mjafi.2016.02.005 PMid:28123249 
11. Walczak DA, Pawełczak D, Żółtaszek A, Jaguścik R, Fałek W, Czerwińska $M$, et al. The value of scoring systems for the diagnosis of acute appendicitis. Pol Przegl Chir. 2015;87(2):6570. https://doi.org/10.1515/pjs-2015-0021 PMid:26146097

12. Cipe G, Idiz O, Hasbahceci M, Bozkurt S, Kadioglu H, Coskun H, et al. Laparoscopic versus open appendectomy: Where are we now? Chirurgia (Bucur). 2014;109(4):518-22.

PMid:25149616

13. Gürleyik G, Gürleyik K, Çetinkaya E, Unalmiser S. Serum interleukin-6 measurement in the diagnosis of acute appendicitis. ANZ J Surg. 2002;72(9):665-7. https://doi. org/10.1046/j.1445-2197.2002.02516.x PMid: 12269920

14. Bealer JF, Colgin MA. S100A8/A9: A potential new diagnostic aid for acute appendicitis. Acad Emerg Med. 2010;17(3):333-6. https://doi.org/10.1111/j.1553-2712.2010.00663.x PMid:20370768

15. March B, Leigh L, Brussius-Coelho M, Holmes M, Pockney P, Gani J. Can CRP velocity in right iliac fossa pain identify patients for intervention? A prospective observational cohort study. Surgeon. 2019;17(5):284-90. https://doi.org/10.1016/j. surge.2018.08.007

PMid:30309747

16. Mengücük $M E$, Ayten $R$, Bülbüller $N$, Gödekmerdan $A$, Bașbuğ M, Mungan I. Role of C-reactive protein, procalsitonin and neopterin in the diagnosis of acute appendicitis. Firat Tip Dergisi. 2010;15:40-3.

17. Fisgin NT, Aliyazicioglu $\mathrm{Y}$, Tanyel E, Coban AY, Ulger F, Zivalioglu $M$, et al. The value of neopterin and procalcitonin in patients with sepsis. South Med Assoc. 2010;13(3):216-9. https://doi.org/10.1097/smj.0b013e3181cf11a1 PMid:20134373

18. Dal F, Cicek Y, Pekmezci S, Kocazeybek B, Tokman HB, Konukoglu D, et al. Role of alvarado score and biological indicators of C-reactive protein, procalicitonin and neopterin in diagnosis of acute appendicitis. Ulus Travma Acil Cerrahi Derg. 2019;25(3):229-37. https://doi.org/10.5505/tjtes.2018.57362 PMid:31135946

19. Coşkun K, Menteş O, Atak A, Aral A, Eryilmaz M, Onguru Ö, et al. Is neopterin a diagnostic marker of acute appendicitis? Ulus Travma Acil Cerrahi Derg. 2012;18(1):1-4. https://doi. org/10.5505/tjtes.2012.00087

PMid:22290042 